\title{
Should We Take the 'Disability' Out of Discrimination Laws? Students with Challenging Behaviour and the Definition of Disability
}

\author{
Karen O'Connell
}

\begin{abstract}
Disability discrimination law has been of limited benefit to people with atypical and challenging behaviour. The role that law might play in upholding the equality rights of people with challenging behaviour is potentially expanded by changing medical and scientific knowledge about such behaviour, which brings more people within the definition of 'disability' and the protective ambit of the law. Yet this protective promise has not translated into legal gains, with few successful equality law cases decided in Australian courts and tribunals. This article critically examines the role of law, particularly anti-discrimination law, in regulating (or protecting) divergent behaviour, using a case study of students with challenging behaviour in Australian schools. It considers the lack of successful discrimination law cases in the education context, and asks whether, given this seeming legislative failure, disability discrimination laws have anything left to offer school students in terms of protecting their equality rights. The article gives an overview of anti-discrimination complaints and cases brought by students with challenging behaviour. It includes interview data from State and federal anti-discrimination bodies, legal practitioners and disability activists to complement case law and other public reports of discrimination. Using this background data, the article considers whether current discrimination law models do enough to protect the rights of students with challenging behaviour to education and inclusion in public life or whether new legal and policy measures are needed. It specifically examines changes to the regulatory landscape, including the Convention on the Rights of Persons with Disability, and whether there are any real prospects for law reform.
\end{abstract}

\section{INTRODUCTION}

My high school years were complete and utter hell.

[B]e yourself, that's all you need to be. Well, a socially acceptable version of yourself haha. ${ }^{1}$

For students with disabilities that make it difficult for them to conform to the usual, sometimes strict, behavioural standards of school life,

1 Thomas Kuzma, 'Feeling Loved' (27 February 2014) and 'Lessons Learned' (16 June 2016) on Autism Spectrum Australia Blog <https://www.autismspectrum.org.au/blog>. 
participating in education can be an ongoing struggle. Challenging behaviour, such as communication deficits, aggressive or odd behaviour, ${ }^{2}$ is a key trigger for exclusion from public life, ${ }^{3}$ not only in education and employment, ${ }^{4}$ but also in use of public spaces, accommodation and access to goods and services. ${ }^{5}$ Challenging behaviour is also associated with a host of disabilities, such as autism spectrum disorder (ASD), attention deficit disorders, intellectual disability and conduct disorders. ${ }^{6}$ Yet challenging behaviour, particularly in children who may seem to be poorly disciplined or badly behaved rather than disadvantaged, can evoke hostile or unsympathetic public and institutional responses. ${ }^{7}$ Law sets out to prevent discriminatory exclusions of people with disabilities from education as well as other areas of public life through the Disability Discrimination Act 1992 (Cth) and similar State and Territory Acts. ${ }^{8}$ Education Standards, regulatory statements adding content and detail to the more broadly expressed right of non-discrimination, have also been developed under the Disability Discrimination Act. ${ }^{9}$ In addition, each of the State and federal anti-discrimination laws specifically covers people

$2 \quad$ Eric Emerson and Jo Bromley, 'The Form and Function of Challenging Behaviours' (1995) 39 Journal of Intellectual Disability Research 388.

3 'Public life' is a complex concept, an arguably artificial demarcation from 'private' life and justifiably and robustly critiqued in feminist literature. However, since Australian discrimination law is founded on access to certain defined areas of 'public' life, I am accepting the distinction for the purposes of this article.

4 Sophie E Moore et al, 'Impact of Adolescent Peer Aggression on Later Educational and Employment Outcomes in an Australian Cohort' (2015) 43 Journal of Adolescence 39.

5 Examples from the Australian Human Rights Commission Conciliation Register include a complaint that a boy with autism was denied access to goods and services when the respondent swimming pool refused his enrolment in group swimming classes (2014), and a complaint that a boy with autism was discriminated against in accommodation when the 'no pets' apartment block his family lived in refused permission for him to have an assistance dog (2012). See $<$ https:// www.humanrights.gov.au/complaints/conciliation-register $>$.

6 See, for example, the list in Megan Shaw, 'Managing Challenging Behaviours with Children Who Have Additional Needs' (2010) 34 Putting Children First 21.

7 Karen O'Connell, 'Bad Boys' Brains: Law, Neuroscience and the Gender of Aggressive Behaviour' in Sigrid Schmitz and Grit Höppner (eds), Gendered Neurocultures: Feminist and Queer Perspectives on Current Brain Discourses (Zaglossus, 2014) 299.

8 Disability Discrimination Act 1992 (Cth) ('Disability Discrimination Act'); Racial Discrimination Act 1975 (Cth); Sex Discrimination Act 1984 (Cth). State anti-discrimination legislation includes: Discrimination Act 1991 (ACT); Anti-Discrimination Act 1977 (NSW); Anti-Discrimination Act 1996 (NT); Anti-Discrimination Act 1991 (Qld); Equal Opportunity Act 1984 (SA); Anti-Discrimination Act 1998 (Tas); Equal Opportunity Act 2010 (Vic); Equal Opportunity Act 1984 (WA). In this article, I focus on federal legislation, although State and Territory legislation significantly overlaps with federal discrimination law.

9 Commonwealth of Australia, Disability Standards for Education 2005 (2006) $<$ https://www.education.gov.au/disability-standards-education-2005>. 
whose disabilities include disturbed behaviour, and/or whose challenging behaviours are a symptom or manifestation of a disability. ${ }^{10}$

Yet this formal discrimination law coverage of students with challenging behaviour does not easily and directly translate into non-discriminatory practices. Challenging behaviour may not be easily traceable to an underlying disability, and even when it is, institutions may lack the capacity or motivation to accommodate difficult, even aggressive, behaviours. The association of 'naughtiness' and poor discipline with challenging behaviour, particularly when exhibited by children or youth, and its evocation of anti-social and criminal behaviour, means that there can also be ambivalence towards extending a protective, rights-based approach to people whose disabilities manifest behaviourally. ${ }^{11}$ Yet children and young people who are excluded from full participation in all aspects of educational life because of a disability ${ }^{12}$ face the possible closing down of further future participation in public life and the compounding of social disadvantages. ${ }^{13}$

The framework of State, Territory and federal discrimination laws also plays a key role in protecting human rights in Australia, which lacks any bill of rights or equivalent protection in its Constitution. Australia's system of discrimination law is therefore at the frontline of ensuring that human rights obligations, including those in the Convention on the Rights of Persons with Disabilities (CRPD), ${ }^{14}$ are met. Yet there are strong concerns expressed by disability advocates, including some of those I interviewed and cite throughout this article, that children with behavioural issues such as those associated with ASD, are experiencing

10 The federal legislation references both of these in its definition of disability (Disability Discrimination Act 1992 (Cth) s 4); the Victorian legislation refers to behaviour as a symptom or manifestation of a disability (Equal Opportunity Act 2010 (Vic) s 4); the other State and Territory Acts refer to disturbed behaviour (Anti-Discrimination Act 1977 (NSW) s 4; Equal Opportunity Act 1984 (SA) s 5; Anti-Discrimination Act 1998 (Tas) s 3; Discrimination Act 1991 (ACT) s 5AA; Anti-Discrimination Act 1996 (NT) s 4; Anti-Discrimination Act 1991 (Qld) Sch (Dictionary); Equal Opportunity Act 1984 (WA) s 4).

11 O'Connell, 'Bad Boys' Brains', above $\mathrm{n} 7$.

12 While the concept of an 'inclusive education' is complex and evolving, human rights standards and current academic research supports inclusion of children with disabilities in all aspects of a mainstream education: UNICEF, The Right of Children with Disabilities to Education: A Rights-Based Approach to Inclusive Education, Position Paper (2012); Kathy Cologon, Inclusion in Education: Towards Equality for Students with Disability, Issues Paper (Children with Disabilities, 2013) 23-35.

13 Both poor educational outcomes and 'challenging behaviour' disabilities are associated with higher incarceration rates. For example, reported prevalence of autism spectrum disorder in juvenile detention is 15 per cent as opposed to 0.6-1.2 per cent in the general population: Kasey Tyler, 'Shining a Light into the Shadows: The Hidden Health Needs of Juveniles in Detention' (2015) 30(2) Alternative Law Journal 101, [102]. See also L Haysom et al, 'Intellectual Disability in Young People in Custody in New South Wales, Australia - Prevalence and Markers' (2014) 58(11) Journal of Intellectual Disability Research 1005.

14 Convention on the Rights of Persons with Disabilities, opened for signature 30 March 2007, 2515 UNTS 3 (entered into force 3 May 2008) (CRPD). 
widespread discrimination and diminished human rights. This is further evidenced in government reports and non-governmental submissions, such as those to the Committee on the Rights of Persons with Disabilities, as well as media reports detailing human rights concerns and sometimes violations. ${ }^{15}$ There are, therefore, urgent reasons to consider whether the discrimination law framework is adequate for protecting the human rights of people with behavioural disabilities. In particular, as I argue below, the CRPD can be the source for a new approach to defining disability where the existing framework is inadequate. In this article, I explore how discrimination law currently responds (or fails to respond) to school-aged children with challenging behaviours, and use the CRPD to argue for an alternative approach to defining disability that shifts the focus away from the individual to the institution.

\section{Challenging Behaviour and Discrimination LaW}

Challenging behaviour presents a new set of problems and opportunities for defining disability in Australian discrimination law. For school-aged children in particular, behaviours that were in the past likely to be seen as individual failures of discipline or character, such as the non-compliance and hostility of Oppositional Defiant Disorder, have now been reframed as disabilities. Yet such behaviours do not fit neatly into traditional legal (usually physical) ways of thinking about impairment. ${ }^{16}$ The key case in the field is Purvis $v$ New South Wales in which the High Court read direct discrimination narrowly to find that a young boy with challenging behaviours, including aggression, could not evoke discrimination law protections to contest his exclusion from school. ${ }^{17}$ Since then there have been a spate of unsuccessful discrimination cases brought by school students with disabilities associated with challenging behaviour, particularly ASD and Attention Deficit Hyperactivity Disorder (ADHD). ${ }^{18}$ The

15 See, for example, Autistic Family Collective, Outline of Concerns Raised by Australian Disability Advocates and Organisations: Report to UN Committee on the Rights of Persons with Disabilities (2016) <http://autisticfamilycollective. org.au/wp-content/uploads/2016/05/Information-sent-to-United-Nations-fromAust-1.doc>; Anthony Shaddock, Sue Packer and Alasdair Roy, Schools for All Children and Young People: Report of the Expert Panel on Students with Complex Needs and Challenging Behaviour (2015) < http://www.det.act.gov.au/_data/ assets/pdf_file/0009/795186/62074-Expert-Panel-Report-Web.pdf> (this report was commissioned following media reports that a Canberra school had built a "cage" for a student with ASD); Victorian Equal Opportunity and Human Rights Commission, Held Back: The Experiences of Students with Disabilities in Victorian Schools (2012), detailing incidents of restraint and seclusion of students with disabilities.

16 Isabel Karpin and Karen O'Connell 'Stigmatising the "Normal": The Legal Regulation of Behaviour as a Disability' (2015) 38(4) University of New South Wales Law Journal 1461.

17 Purvis v New South Wales (2003) 217 CLR 92.

$18 R W v$ Victoria (Human Rights) [2015] VCAT 266; Lambert $v$ Victoria [2014] FCA 1064; USL obo her son v Ballarat Christian College (Human Rights) [2014] 
reasons for these failures vary, but at least one reason is the difficulty of expanding disability discrimination law protections to behaviour cases. ${ }^{19}$

Cases represent only the tiniest proportion of discrimination law complaints. A significant filtering process from complaints to case law, means that decided cases are not representative of the scope or nature of discrimination in practice. ${ }^{20}$ Discrimination complaints brought to equal opportunity commissions, while far more numerous, are also confidential, meaning that this is a field of law that is largely shielded from public scrutiny. Interview data can thus be particularly useful in analysing discrimination law issues, as it reaches the knowledge held by active participants in the system: complainants, respondents and conciliators, along with legal representatives or advocates the parties may engage. ${ }^{21}$

This article references data from two projects examining challenging behaviour as a disability, using interview data, along with case law and complaints data. ${ }^{22}$ I focus on one aspect of the interview data: how my interviewees reflected on the way that disability, and specifically challenging behaviour as a disability, is understood and defined. ${ }^{23}$ Their

VCAT 623; Kiefel v Victoria [2013] FCA 1398; AB v Ballarat Christian College (Human Rights) [2013] VCAT 1790; Sievwright v Victoria [2013] FCA 964; Abela $v$ Victoria [2013] FCA 832; Walker v Victoria [2012] FCAFC 38; Walker $v$ Victoria (2011) 279 ALR 284; Phu $v$ NSW Department of Education and Training [2010] NSWADT 152; Mason v Methodist Ladies College [2009] FMCA 570; Ives v Kilvington Grammar Ltd [2008] FMCA 1414. Almost all of the cases on disability discrimination in schools have been behaviour cases, and none of these have been successful. Most were Victorian cases, supported by active advocacy services in that State. Only a few additional cases have dealt with physical, sensory or learning disabilities. For an analysis of some these cases see O'Connell, 'Bad Boys' Brains', above n 7 .

19 O'Connell, 'Bad Boys' Brains', above n 7; Karen O'Connell, 'Unequal Brains: Disability Discrimination Laws and Children with Challenging Behaviour' (2016) 24(1) Medical Law Review 76.

20 In 2014-2015, the Australian Human Rights Commission received 2,388 complaints across all grounds of discrimination (sex, race, disability and age). There were 740 disability discrimination complaints, and 99 of these were disability discrimination in the area of education. Only a fraction of these continued to the Federal Court, where more settle, and a tiny number proceed to determination. See Australian Human Rights Commission, Annual Report 2014-2015 (2015) 136. Dominique Allen describes this filtering process across three jurisdictions (Queensland, Victoria and federal) in 2006-2007: Dominique Allen, 'Behind the Conciliation Doors' (2009) 18(3) Griffith Law Review 778, 779-782.

21 Allen, above n 20, 783.

22 A University of Technology Sydney Chancellor's Postdoctoral Fellowship on 'Equality Laws in the Biotechnological Age' (2010-2015) (UTS HREC Ref No 2014000013), and a current Australian Research Council Discovery Project with Professor Isabel Karpin on 'The Legal Regulation of Behaviour as a Disability' (Project No DP150102935). In the first, I conducted a case study of discrimination against school students with challenging behaviour, including the interviews quoted in this article, and in the second, Karpin and I are researching the way that social stigma and inequalities manifest in the body as biological effects and disabilities, and how law responds to those inequalities.

23 I interviewed 23 professionals and advocates directly or indirectly involved in disability discrimination work. Interviewees were from New South Wales, 
comments and criticisms led me to consider whether having a definitional hurdle of 'disability' in discrimination law served a useful purpose, or in fact if it was needed at all, and it is this question that this article ultimately addresses. It is aimed at opening up a discussion about what we are trying to address with disability discrimination laws and whether we need to limit the people who can access those laws or whether removing the definitional hurdle of 'disability' might usefully expand their scope and effectiveness.

Opening up disability discrimination law to people who may not meet a definition of disability is not the 'floodgates' issue that it may seem. Discrimination legislation contains other hurdles for complainants that resist its scope, most significantly, that adjustments for people with disability are required only if they are reasonable. ${ }^{24} \mathrm{I}$ will argue below that a more appropriate focus for discrimination law is whether institutions are doing enough to reasonably accommodate participants. The nature of a particular impairment may still be relevant to a consideration of what is or is not 'reasonable'. However, removing the definition could have the significant benefit of shifting the focus away from individual bodies or behaviour to institutions. Using the case of 'challenging behaviour', I argue that a legislative focus away from individual characteristics and towards institutional ones takes us closer to implementing a human rights approach to disability discrimination.

\section{What Is 'Challenging Behaviour'?}

Before 'challenging behaviour' can be defined, how 'behaviour' is understood is crucial in analysing how disability discrimination law works in practice. A standard, dictionary definition of behaviour has a primary meaning: 'the way in which one acts or conducts oneself, especially towards others', but also a more contextual meaning: 'the way in which an animal or person behaves in response to a particular situation or stimulus.' ${ }^{25}$ Disability advocates and service providers I interviewed emphasised behaviour in this latter sense as a co-creation between individuals and a specific environment. An environment could be hostile to a person with ASD, for example, if it was unpredictable or sensorily overwhelming. Environmental triggers for poor social behaviours were pointed out by

Victoria, Queensland, Tasmania, South Australia and Western Australia, and included equal opportunity complaints staff, current and past equal opportunity commissioners, disability advocates and service providers, staff from government departments and non-government organisations, community legal staff and teachers.

24 Disability Discrimination Act 1992 (Cth) s 5(2) clarifies that direct discrimination includes the failure to make reasonable adjustments; s 6(3) states that indirect discrimination - the imposition of a disadvantageous requirement or condition - is not unlawful if reasonable. Only s 5(1) (direct discrimination) has no reasonableness limitation.

25 English Oxford Living Dictionary <https://en.oxforddictionaries.com/definition/ behaviour>. 
one interviewee as discriminatory in the same way that physical barriers might be for a person in a wheelchair. ${ }^{26}$ On this view, responsibility for the resulting behaviours was also, therefore, shared, and could not be simply attributed to an individual. One service provider criticised judgmental descriptors such as 'aggressive' or 'violent' for behaviour, instead seeing even very challenging behaviours as an attempted communication, and the true 'challenge' being to understand what the person was trying to communicate with their behaviour. ${ }^{27}$

Clearly, this approach is not uncontentious since it seems to undermine individual responsibility for behaviour, a principle that underpins both criminal and civil law, albeit with exceptions. ${ }^{28}$ Negative judgments against school students with behavioural issues, such as in the case of Purvis described above, have included judicial pronouncements indicating that discrimination law should not protect 'criminal' behaviour or behaviour that indicates 'volition'. ${ }^{29}$ There are some challenging behaviours that will not be able to be reasonably accommodated, and some that themselves target other vulnerable individuals or groups. ${ }^{30}$ This judicial concern can, however, be criticised for anticipating criminality in children and young people who are demonstrating an inability to cope in a stressful, hostile environment rather than a latent criminality. I have written elsewhere on how the spectre of criminality undermines a more sympathetic and nuanced approach to the 'badly' behaved child in discrimination law. ${ }^{31}$

However, without dismissing these concerns, the idea of behaviour as a co-creation, with responsibility attributed to both the individual and the institutional context, is one that fits well into discrimination law in its most transformative aspect. Just as behaviour has both individual and contextual definitions, disability discrimination law attempts to incorporate an individual complaints-based approach that emphasises distinct, impliedly exceptional, incidents of harm, along with a contextual, or systemic approach, through 'disability standards' and 'action plans', that makes institutions and even entire sectors, such as the education sector, responsible for positively addressing discrimination. ${ }^{32}$

26 Interview with a discrimination practitioner (2014).

27 Ibid.

28 Such as vicarious liability in civil law, including employment and sexual harassment.

29 Purvis v New South Wales (2003) 217 CLR 92, 98; USL obo her son v Ballarat Christian College (Human Rights) [2014] VCAT 623, [79].

30 Karen O'Connell, 'Eccentricity: The Case for Undermining Legal Categories of Disability and Normalcy' (2017) 31(3) Continuum: Journal of Media and Cultural Studies 352. Walker v Victoria (2011) 279 ALR 284 involved a young boy who targeted a younger girl with sexualised insults and the complainant in USL obo her son v Ballarat Christian College (Human Rights) [2014] VCAT 623 made racially offensive comments.

31 O'Connell, 'Bad Boys' Brains', above n 7; O'Connell, 'Unequal Brains', above n 19.

32 Lee Ann Basser and Melinda Jones 'The DDA and the Tripartite Approach to Operationalising Human Rights' (2002) 26 Melbourne University Law Review 254. 
In describing this more fully below, I will argue that challenging behaviour offers opportunities to rethink how we balance these, and suggests that a move towards a more contextual and systemic approach is needed.

What makes behaviour 'challenging' and when such behaviour should be considered a disability requires another layer of interpretation. Challenging behaviour is defined in the social science and medical literature as behaviour that causes harm to the self or others, or interferes with a person's participation in public life, including, for example, 'behavior which is likely to seriously limit use of, or result in the person being denied access to, ordinary community facilities' ${ }^{33}$ Since Australian discrimination law is directed at increasing participation in key arenas of public life (education, employment, the provision of goods and services) it is this 'likelihood of exclusion' aspect of the definition that is of particular interest here. The definition is slippery and contingent: behaviour is 'challenging' when a society cannot tolerate it and it results in public exclusion. Thus, 'challenging' behavior is not only measured by biological characteristics but by what is deemed socially unacceptable.

Challenging behaviour, which largely falls within the arena of disability, can also carry with it other forms of stigma. This is because what is considered socially acceptable varies according to other aspects of identity such as gender and race. In the school context, boys, for example, may be expected to be more active and even aggressive, while girls exhibiting such behaviour may be more harshly judged. Where challenging behaviour is associated with a disability, evidence shows that diagnosis of disabilities varies by race in ways that are not objectively explainable. ${ }^{34}$ Australian research on school students shows that the more subjective the set of criteria for a particular disability, the more likely it is that diagnosis will be skewed by gender, with boys over-represented in various degrees across all categories of disability. ${ }^{35}$

The definition of 'challenging behaviour' acknowledges the importance of these social influences, particularly that the meaning of behaviour is as much about context as individual qualities, but there has been 'a drift towards using the term simply as a diagnostic label'. ${ }^{36}$ As scientific knowledge expands, there is an increasing tendency to emphasise biological

$33 \quad$ Eric Emerson and Stewart Einfeld, Challenging Behavior (Cambridge University Press, 3rd ed, 2011) 3. See also Eric Emerson and Jo Bromley, above n 2, 388-398.

34 Ruth Colker, Disabled Education: A Critical Analysis of the Individuals with Disabilities Education Act (NYU Press, 2013) 89. In Australia, data are not available to show the racial identities of school students with disabilities: see Linda Graham et al, 'Detaining the Usual Suspects: Charting the Use of Segregated Settings in New South Wales Government Schools, Australia' (2010) 11(3) Contemporary Issues in Early Childhood 234.

35 Penny Bergen et al, 'The Psychology of Containment: (Mis)representing Emotional and Behavioural Difficulties in Australian Schools' (2015) 20(1) Emotional and Behavioural Difficulties 64; Graham et al, above n 34.

36 Emerson and Einfeld, above n 33, 5. See also Rob Greig, Challenging Behaviour: A Unified Approach, College Report CR144 (Royal College of Psychiatrists, British Psychological Society and Royal College of Speech and Language Therapists, 2007) 5. 
and medical elements of behaviour over the social construction of challenging behaviour. This approach is further entrenched with current and emerging research into the genetic and neurological underpinnings of various socially challenging behaviours, from addiction to attention deficits to aggression. ${ }^{37}$ Behaviour becomes increasingly embedded in a biomedical framework, and therefore more likely to be seen as part of an expanded category of 'disability', even before the scientific links between behaviour and biomarkers have been established. As Karpin and I have written: 'the conviction that these biomarkers exist and are simply waiting for proper scientific measurement and full revelation means that these 'disorders' are, in the meantime, treated as biologically meaningful.' ${ }^{38}$

Challenging behaviours are increasingly linked to a range of disabilities, both diagnostically and in discrimination law. In discrimination complaints and case law, challenging behavior is associated most commonly with ASD, ADHD, conduct disorders (such as Oppositional Defiant Disorder) and intellectual disabilities. ${ }^{39}$ Many of these disabilities are increasing in incidence. The number of Australians with ASD, for example, almost quadrupled between 2003 and 2012.40 In New South Wales, public school students with an ASD or mental health diagnosis tripled between 2003 and $2011 .^{41}$ Why the rate of these disabilities is

37 See, for example, Adrian Carter and Wayne Hall, 'The Social Implications of Neurobiological Explanations of Resistible Compulsions' (2007) 7(1) American Journal of Bioethics 15; Allan Siegal and Jeff Victoroff, 'Understanding Human Aggression: New Insights From Neuroscience' (2009) 32 International Journal of Law and Psychiatry 209; Rosemary Tannock, 'Attention Deficit Hyperactivity Disorder: Advances in Cognitive, Neurobiological, and Genetic Research' (1998) 39(1) Journal of Child Psychology and Psychiatry 6; Brett Abrahams and Daniel Geschwind, 'Advances in Autism Genetics: On the Threshold of a New Neurobiology' (2008) 9 Nature Reviews Genetics 341.

38 Karpin and O'Connell, above n 16, 1465.

39 The Australian Human Rights Commission Conciliation Register, for example, refers to a complaint about the exclusion of a boy from an after-school care centre because of behaviour associated with his disabilities (ADHD and Oppositional Defiant Disorder). Other complaints relate to the suspension of a 13-year-old boy with Asperger's Syndrome and ADHD due to behaviour associated with his disability, and to the suspension of a boy, with a number of disabilities including ASD, from school due to escalating aggressive behaviour, for the safety of other students and staff. See <https://www.humanrights.gov.au/complaints/ conciliation-register>.

40 Australian Bureau of Statistics, 'Prevalence of Autism' (3 June 2014) in 4428.0 - Autism in Australia, 2009 (2011) <http://www.abs.gov.au/AUSSTATS/ abs@.nsf/Previousproducts/4428.0Main\%20Features42009>; Australian Bureau of Statistics, 'Prevalence of Autism' (3 June 2014) in 4428.0 - Autism in Australia, 2012 (2014) <http://www.abs.gov.au/AUSSTATS/abs@.nsf/ Latestproducts/4428.0Main\%20Features32012>.

41 New South Wales Department of Education, document provided to O'Connell, 17 February 2012. In addition, '[t]he percentage of students with disabilities in primary schools doubled between 1995 and 2006 as anti-discrimination policies funnelled kids into a mainstream setting': Kate Legge, 'The Autism Explosion in Australian Schools', The Australian (online), 16 January 2016 
growing so dramatically is a point of contention, but one reason often given is the increase in social awareness of disabilities with behavioural components and, correspondingly, in diagnosis. ${ }^{42}$

In some respects, it is a beneficial change for students with challenging behaviour to be associated with disability, since this gives access to medical and psychological treatments and brings them within the protective zone of discrimination law. This potential access to legal protection, however, comes at a cost, because it requires the child to take on a stigmatised social identity as 'disabled', whether or not the child understands the consequences of that label or identifies with it, and to accept their status as presumptively outside the mainstream. ${ }^{43}$ Also, when challenging behaviours do seem to arise from disabilities, this does not necessarily make their categorisation simple. 'Disability' is as difficult a word to define as 'behaviour', and just as socially constructed.

\section{Where Does (and Where Should) Disability 'Reside'? DiscRimination LAW AND the Definition of Disability}

In Australian federal discrimination law, disability is defined broadly. ${ }^{44}$ The breadth of the definition was specifically intended, according to

$<$ http://www.theaustralian.com.au/life/weekend-australian-magazine/theautism-explosion-in-australian-schools/news-story/7b0b56a5f5c9f6525dedffc8d $7 \mathrm{f} 6 \mathrm{e} 5 \mathrm{~d} 8>$.

42 Stefan N Hansen, Diana E Schendel and Erik T Parner, 'Explaining the Increase in the Prevalence of Autism Spectrum Disorders: The Proportion Attributable to Changes in Reporting Practices' (2015) 169(1) JAMA Pediatrics 56; Ginny Russell and Brahm Norwich, 'Dilemmas, Diagnosis and De-Stigmatization: Parental Perspectives on the Diagnosis of Autism Spectrum Disorders' (2012) 17 Clinical Child Psychology and Psychiatry 229; John N Constantino and Tony Charman, 'Diagnosis of Autism Spectrum Disorder: Reconciling the Syndrome, its Diverse Origins, and Variation in Expression' (2016) 15 Lancet Neurology 279.

43 Parents also understandably struggle with the idea of 'labelling' their child as disabled. In the unusual case of CLW v New South Wales (Department of Education and Communities) [2016] NSWCATAD 43, the divorced parents of a school child disagreed over whether their son had ASD. The mother brought a complaint against the Department, arguing that it had discriminated against her son on the grounds of 'presumed' disability by placing him in a school autism intervention program.

44 Section 4 of the Disability Discrimination Act 1992 (Cth) defines 'disability' as: '(a) total or partial loss of the person's bodily or mental functions; or (b) total or partial loss of a part of the body; or (c) the presence in the body of organisms causing disease or illness; or (d) the presence in the body of organisms capable of causing disease or illness; or (e) the malfunction, malformation or disfigurement of a part of the person's body; or (f) a disorder or malfunction that results in the person learning differently from a person without the disorder or malfunction; or (g) a disorder, illness or disease that affects a person's thought processes, perception of reality, emotions or judgment or that results in disturbed behaviour; and includes a disability that: (h) presently exists; or (i) previously existed but no longer exists; or (j) may exist in the future (including because of a genetic 
former Disability Discrimination Commissioner, Graeme Innes, who worked on the legislation, to be as inclusive as possible. ${ }^{45}$ In addition, the Disability Discrimination Act was, and remains, a unique piece of Australian discrimination legislation for its attempts to attribute responsibility for disability from individuals through to whole sectors of society. ${ }^{46}$ It establishes a system for sharing responsibility for discrimination between individuals (the complaints system), institutions (through creating a mechanism for developing institutional 'action plans' to proactively prevent discrimination) and community sectors such as education (through the creation of 'standards').

The Australian legislation can be contrasted with narrower definitions in other jurisdictions, which exclude many possible cases of discrimination from protection because of more stringent definitional hurdles. For example, the Equality Act 2010 (UK) defines a disability as a 'physical or mental impairment' with 'a substantial and long-term adverse effect on [the person's] ability to carry out normal day-to-day activities'. ${ }^{47}$ Lawson writes critically of the limiting requirements of 'substantial', 'long-term' and inability to carry out 'normal day-to-day activities'. As will be described below, requirements such as these would potentially exclude behaviour as a disability, which is fluctuating and contextual. Lawson states that 'the disability definition requirement risks distracting judicial and other attention from the behaviour of the alleged discriminator and focusing it instead on the functional limitations of the victim'. ${ }^{48}$

Almost one-fifth of all disability discrimination tribunal cases in the UK are estimated to fail because of the disability definition. ${ }^{49}$ Despite the breadth of the definition in Australian discrimination law, the attention is still placed on the individual. Arguably, this is because any individual legislative definition of disability draws attention to the impairment or limitation of the complainant as the expense of more systemic considerations.

Where the 'attention' in discrimination law should lie is a crucial question because it goes directly to the attribution of responsibility for accommodating behaviour. The Australian federal legislation was influenced by the 'social model' of disability. ${ }^{50}$ This model attempts to shift attention, including legal attention, away from the body of the person with the impairment, to the society that sets up the conditions for exclusion

predisposition to that disability); or ( $\mathrm{k}$ ) is imputed to a person. To avoid doubt, a disability that is otherwise covered by this definition includes behaviour that is a symptom or manifestation of the disability.'

45 Interview with Graeme Innes (2014).

46 Basser and Jones, above $\mathrm{n} 32$.

47 Equality Act 2010 (UK) s 6.

48 Anna Lawson, 'Disability and Employment in the Equality Act 2010: Opportunities Seized, Lost and Generated' (2011) 40(4) Industrial Law Journal $359,363$.

49 Ibid.

50 Basser and Jones, above n 32. 
and unequal treatment. The social model promotes a simple but powerful idea: that it is society that disables people, since it is the social barriers to participation that create the disability, not the individual impairment. ${ }^{51}$ The social model has also been criticised for this simplicity, which some have argued is reductive, because it ignores the embodied experience of disability ${ }^{52}$ and assumes that all impairments can be addressed through social change. ${ }^{53}$ Shakespeare calls the social model a 'blunt instrument' for combating social exclusion, and writes that it is 'unhelpful for understanding the complex interplay of individual and environmental factors in the lives of disabled people'. ${ }^{54}$

A more complex model sees the body as 'simultaneously biological, material and social' ${ }^{55}$ and disability as an interplay of complex individual and social factors. The closest law has come to a definition that sees disability as a co-creation is the CRPD, which states:

Recognizing that disability is an evolving concept and that disability results from the interaction between persons with impairments and attitudinal and environmental barriers that hinders their full and effective participation in society on an equal basis with others. ${ }^{56}$

This definition acknowledges that disability is not a static descriptor of a set social status: it is 'evolving' over time. As well as impairments in an individual, it explicitly references two other factors: 'attitudinal' barriers and 'environmental' barriers. In other words, disability is created in the body, in the minds of others, and in the environment in which each of these is embedded. The public and institutional targets of discrimination law are similarly creations of bodies, minds and environments, and have disabling qualities that are not static over time.

What would happen if we implemented this definition in Australian discrimination law? After setting out the challenges posed to law by challenging behavior, I argue that disability discrimination law should be inspired by the CRPD to move away from a focus on defining individual attributes of 'disability' in favour of targeting 'disabling' institutions.

51 Dana Lee Baker, 'Autism as Public Policy' in Dianne Pothier and Richard Devlin (eds), Critical Disability Theory: Essays in Philosophy, Politics, Policy, and Law (UBC Press, 2006) 177.

52 See, for example, Susan Wendell, The Rejected Body: Feminist Philosophical Reflections on Disability (Routledge, 1996).

53 Jackie Leach Scully, Disability Bioethics: Moral Bodies, Moral Difference (Rowman \& Littlefield, 2008) 26.

54 Tom Shakespeare, 'The Social Model of Disability' in Lennard J Davis (ed), The Disability Studies Reader (Routledge, 2nd ed, 2006) 197, 202; Tom Shakespeare and Nicholas Watson, 'The Social Model of Disability: An Outdated Ideology?' (2002) 2 Research in Social Science and Disability 9.

55 Carol Thomas, Female Forms: Experiencing and Understanding Disability (Open University Press, 1999), as cited in Leach Scully, above n 53, 29.

CRPD Preamble. 


\section{The 'Challenge' of Defining Challenging Behaviour as a Disability in Discrimination LaW}

Given its origins in the social model of disability ${ }^{57}$ and its explicit inclusion of 'behaviour', the Disability Discrimination Act and similar State discrimination law definitions should be well equipped to respond to challenging behaviours that are a symptom or manifestation of a disability, and to respond in a way that fully accounts for context, for behaviour as a 'co-creation' of the individual and for the environment. However, there are particular assumptions about, and responses to, people with challenging behaviour that make discrimination in this area particularly acute and hard to target.

\section{A 'It's Like You Need a Doctor's Certificate to Have a Disability': The Misconception that Disability Must Be Diagnosed or Treated}

The social model sits in opposition to a medical approach to disabled identity that is counter-productive to legal and policy measures to protect disability rights. Shakespeare writes that key to the struggle against 'the historical oppression and exclusion of disabled people ... has been the challenge to over-medicalized and individualist accounts of disability'. ${ }^{58}$ Nevertheless, discrimination law continues to be impacted by the misconception that disability necessarily has a medical component, and this is especially the case when dealing with behavioural issues.

There is no requirement in discrimination legislation that a person have a diagnosis in order to meet the definition of disability. However, the idea that disability is a medical condition, and therefore needs a diagnosis, is so deeply entrenched that even the decades-old critique of the medical model has not completely dislodged it. For children with disabilities manifesting in challenging behaviour, the uncertainty that surrounds behaviour as a disability - is it a disability or merely 'bad' behaviour? means that they are particularly susceptible to the seemingly objective measure of a diagnosis.

It's like you need a doctor's certificate to have a disability. No you don't. Diagnosis can assist you in determining whether a disability exists, but it's the functionality that's the real question ... The emergent disabilities, particularly in the behavioural space, [are] particularly complicated. ${ }^{59}$

In practice, this medical approach means that where a diagnosis is absent, the child may be treated as if they do not have a disability, even when they are not functioning well in the school environment.

$57 \quad$ Elizabeth Dickson, 'Understanding Disability: An Analysis of the Influence of the Social Model of Disability in the Drafting of the Anti-Discrimination Act 1991 (Qld) and in its Interpretation and Application' (2003) 8(1) Australia \& New Zealand Journal of Law \& Education 47.

58 Shakespeare, above n 54, 197.

59 Interview with a discrimination law practitioner (2014). 
There is a little boy in there who is not diagnosed but ... his behaviour is almost like he's out of control all the time ... You say go sit by the door - he doesn't care ... He sits by the door and [screams]. I know last year the teacher had a lot of trouble with him because he used to run up and down the classroom [shouting] - 'fuck you, fuck you, fuck you' ... and because there's no diagnosis there's no support time given. You can't do much without a diagnosis. ${ }^{60}$

In this case, the child's lack of a diagnosis meant that he was not eligible for additional funding under State government regulations, and his disturbed behaviour was just accommodated as best the individual classroom teachers could manage. The teacher's repeated reference to the absence of a diagnosis, in relation to a child who is clearly in desperate need of support, is a poignant reminder of the potential material consequences when a child is not defined as having a disability.

The case law also reflects an emphasis on clinical diagnosis. While evidence of a disability is required, ${ }^{61}$ this need not be from a medical diagnosis, but where advocates have attempted to shift the focus to the child's inability to function in the school environment, this has not been sufficient to prove disability. In USL obo her son v Ballarat Christian College, a case brought by a mother regarding the rapid academic deterioration and exclusion from school activities experienced by her son, who had ADHD and had behaved badly that year at school, Harbison J states:

One of the surprising features of this case was that although a great deal of attention was given in the case to measures taken (or not taken) by the school in response to the child's alleged disability, the evidence of treating clinicians about that disability was almost entirely absent. ${ }^{62}$

When the mother's representative responded that a diagnosis is not required, and cited case law to that effect, the judge responded by agreeing that the focus should be on the behaviours arising from the disability, but that the existence of disability must still be established as a 'matter of fact'. ${ }^{63}$ The fact of disability, it is implied, is evidenced by treating clinicians, based on an assumption of medical treatment, not, as the representative would have it, by evidence of the child's inability to function in the school environment.

If disability is best evidenced by diagnosis, this will not necessarily suit children with disabilities such as ASD, ADHD or conduct disorders. Parents sometimes choose not to have their child formally diagnosed, in order to avoid a stigmatising label. These are also not disabilities that necessarily require medical treatment, as some parents find that it is non-medical treatments that work best for their child: routines and predictability, time spent in low stress environments, support groups, etc. Whatever the choices made, this is not an area where children necessarily

60 Interview with an education professional (2014).

61 Qantas Airways Ltd v Gama [2008] FCAFC 69.

62 USL obo her son v Ballarat Christian College (Human Rights) [2014] VCAT 623, [18].

63 Ibid. 
have a 'treating clinician', or in fact, a diagnosis, yet the absence of these does not mean that they are able to function in environments that are hostile or poorly accommodate their needs.

The Committee on the Rights of Persons with Disabilities has made it very clear in its recent General Comment on Education that the 'diagnostic' approach is wrong: 'Provision of reasonable accommodation may not be conditional on a medical diagnosis of impairment and should be based instead on the evaluation of social barriers to education. ${ }^{64}$ In other words, the focus should be on whether a child can in fact access education, not on their medical status. Despite this, the emphasis on diagnosis continues. The focus on impairment in Australian case law needs to be addressed with an amended definition that either specifically states that diagnosis is not required, or by emphasising social components in the definition of disability, not only individual impairment. One way this could be done, as I discuss further below, is to completely remove the individual definition of disability from the legislation.

\section{B Multiple Intersecting Definitions of 'Disability' Do Not Serve People with Challenging Behaviour Well}

Definitions in other areas of disability regulation, such as funding for additional support for students with disabilities, also confuse the issue of where and when disability exists. There is no single definition of disability. ${ }^{65}$ In law, disability is defined differently according to the different purposes the definition needs to serve. However, the overlap with other, narrower, definitions of disability can confuse how a child should be treated in relation to discrimination law and their right to an equal education. In the school context, the broad discrimination law definition of 'disability' is undermined by a more restrictive school funding definition by the relevant State education departments. This means that a child with behavioural issues that would meet the disability discrimination definition would not necessarily meet a school funding definition. For example, the New South Wales Department of Education Disability Criteria for school funding support has detailed, narrow criteria for disability. Mental health problems, in order to be recognised as a disability, must satisfy criteria that include the following.

Students must exhibit behaviour(s) that is characteristic of mental health problems at a level of frequency, duration and intensity that seriously affects their educational functioning and emotional well-being. The

$64 \quad$ Committee on the Rights of Persons with Disabilities, General Comment No 4: Article 24: Right to Inclusive Education, UN Doc CRPD/C/GC/4 (24 August 2016) [29].

65 World Health Organization, Disabilities (2016) <http://www.who.int/topics/ disabilities/en/>; World Health Organization, International Classification of Functioning, Disability and Health (ICF) (22 July 2016) <http://www. who.int/classifications/icf/en/>; Australian Institute of Health and Welfare, Technical Definitions of Disability (2016) < http://www.aihw.gov.au/disability/ technical-definitions-of-disability/>. 
behaviour(s) must be evident in the home, school and community environments. Students must have a current report from a specialist medical practitioner or registered psychologist with appropriate clinical experience which details the nature of the behaviour(s). ${ }^{66}$

These criteria impose conditions of 'seriousness', require that the behaviour be displayed across multiple environments (undercutting the idea that behaviour varies by context), and the student must effectively have a diagnosis from a doctor or psychologist. Once a child has failed to meet the relatively stringent definition of disability for school funding, it is easy for parents and teachers to assume that the child is not then 'disabled' in other contexts. The child may still fall within the broad disability discrimination law protections, however, a negative school funding diagnosis can have a chilling effect on a child's education rights. Where a child does meet the narrower definition, a host of positive consequences for their education can flow from that.

If you've got a diagnosis that says I have this, that or the other ... and then you have the proof from the doctor and you fill in the required paperwork, you get money. That money ultimately means extra support people, and having someone work with that child or within their classroom can make a massive difference socially, emotionally and to their academic development. ${ }^{67}$

Where a child narrowly misses out, they may still have high needs but no financial support, as happened in the case of Sievwright $v$ Victoria where a young girl who was originally defined as intellectually disabled and able to receive support funding then slightly improved on her psychological assessment, meaning that she no longer qualified for further support. ${ }^{68}$

The fact that the relatively broad definition of disability in discrimination legislation sits alongside narrower definitions of disability, particularly in the school context, is another reason to reform the discrimination law definition, to clarify that it should not be undermined by narrow definitions designed to restrict access to funding.

\section{There is a Lack of Understanding of Behaviour as a Disability}

Having an 'invisible' disability, and one that can be seen as a negative variant of 'normal', makes challenging behaviour difficult to understand and to accommodate for many people, as Arnold et al point out in relation to ADHD.

Differences in ability associated with ADHD are not physical or visible and behaviours that characterise ADHD are experienced by most people from time to time so that they tend to be seen as 'normal'. As a result, tolerance

$66 \quad$ New South Wales Department of Education and Training, Disability Criteria (School Sector) (2003) <https://www.schools.nsw.edu.au/media/downloads/.../ disabilitypgrms/disabcriteria.doc $>$.

67 Interview with an education professional (2014).

68 Sievwright $v$ Victoria [2013] FCA 964; see also Michelle Griffin, 'Disabled Student's Lawsuit Fails', The Age (Melbourne), 22 February 2012. 
of the behavioural differences that characterise people with ADHD tends to be low and there is an expectation that they will conform to normal expectations. ${ }^{69}$

In certain contexts, this low tolerance will be exacerbated. For example, school is an institution where standards of behaviour are set, standardised and enforced, with disciplinary consequences for non-compliance. Further, and despite the increasing biologisation of behaviour, bad behaviour, particularly when displayed by a school child, is still commonly seen as a disciplinary issue, 'dismissed as naughty behaviour or then down the track criminal behavior', ${ }^{70}$ which a school is expected to remedy, not accommodate.

Behavioural issues in schools also impact teachers and other children in ways that can be seen as undermining their education goals.

If it's a physical disability and you can see something, you can do the accommodation, it's not hard. But the argument ... around I don't want someone who is going to be behaving badly and distracting all the other students and my son or daughter in the classroom, is a big, strong argument. ${ }^{71}$

One advocate compared a failure to accommodate behavioural differences as equivalent to trying to force someone in a wheelchair to go up stairs. He pointed out how ridiculous it would be to say to people in wheelchairs that they are 'challenging' or 'non-compliant' because they cannot operate in a physically hostile environment.

People with an obvious physical disability have a right to have an environment that supports their needs. When it comes to autism, it's really hard to get that message across. ${ }^{72}$

\section{Challenging Behaviour is Contextual, Making it Unclear When it is a Disability}

Given that what is understood as 'problem' behaviour is shaped by social attitudes in a particular context, challenging behaviour is not necessarily an inherent part of a disability in isolation from particular external triggers. The context in which behaviour takes place may determine the nature and severity of the legal response. A legal practitioner who works with children in out-of-home care commented that children who might behave badly within their own families have that behaviour managed privately, whereas a child in a group home is much more likely to have police called, even for 'ordinary' bad behaviours such as hitting a sibling or smashing an object. ${ }^{73} \mathrm{~A}$ discrimination law practitioner described a repeat discrimination complainant, an adult with challenging behaviour:

69 Arnold et al, 'It Just Doesn't ADD Up: ADHD/ADD, the Workplace and Discrimination' (2010) 34(2) Melbourne University Law Review 359, 367.

70 Interview with a discrimination law practitioner (2014).

71 Interview with a disability advocate (2014).

72 Interview with a disability advocate (2014).

73 Interview with a legal practitioner (2014). 
Part of the problem is, people see him and he'll sit in the conciliation and he won't swear. He'll be entirely well behaved. The respondents see that and they go, see, he can behave himself. It's like, yeah okay. Let's take this into context. He's in a calm environment, where he's got an impartial person controlling the room. He knows he's not about to be arrested. He knows he's not about to be subjected to violence. He's not going to escalate. It's just not going to happen, so don't use that as justification to say he can always control his behaviour, because it's not [a justification]. It's context-driven stuff. ${ }^{74}$

A similar issue was raised in $A B v$ Ballarat Christian College, where a young boy, AB, with ASD and a language disorder was prevented from attending his school camp because of bad behaviour. ${ }^{75} \mathrm{He}$ argued that this was discriminatory, but was unsuccessful, because he had demonstrated acceptable behaviour at other times throughout his schooling. Since he had shown a capacity to control his behaviour in the past, the tribunal decided that his recent 'bad behaviour' was not due to his disability but to other factors not protected by law.

While it seems wrong to attempt to hold people with behavioural disabilities to some consistently unvarying, and unrealistic, standard of 'bad' behaviour to evoke discrimination law protections, this nevertheless exposes a problem regarding how to connect the behaviour to the underlying disability. It is also clearly wrong to claim a complete lack of volition, as if a person with challenging behaviour can never choose to behave badly.

[P] eople just put [behavioural disability] down to being naughty. I mean each kid's different and some people with disability are also naughty. ${ }^{76}$

The decision about when behaviour is a disability and when it is not will always be complex. However, accepting that behaviour is contextual also means that the behaviour is not only because of the individual attributes of the person, but because of their attributes in that particular environment and set of relationships. What exactly it is about the environment and the person, together, that creates behaviour is a more difficult but also more useful question.

\section{E When Challenging Behaviour Arises from Trauma and Social Disadvantage}

An issue that falls outside of the scope of discrimination law, but perhaps should not, is what to do about behaviour that leads to social exclusion but is not a symptom or manifestation of a disability. Should, perhaps, everyone have a right to equal treatment, where reasonable, regardless of whether the challenging behaviour is associated with a disability or not?

Some of the interviews I conducted on challenging behaviour were in a remote Aboriginal community. In that context, very few children

74 Interview with a discrimination law practitioner (2014).

75 AB v Ballarat Christian College [2013] VCAT 1790.

76 Interview with a discrimination law practitioner (2014). 
were formally diagnosed with a disability, or necessarily treated by their teachers as if they had a disability, and yet there were overwhelming numbers of children with extremely disturbed or distressed behaviours that prevented them learning. One of these children was the boy described above, who was consistently out of control in his language and behaviour. Another child was disturbingly passive and detached.

One girl in particular was very happy, very bright - her parents left to go to Perth and they left her here. Another parent found her and she was starving and very dehydrated ... Now she is very reserved. When she gets dropped off at school she stands in the door and she won't go anywhere. You can say - come in, choose something to do - but she just stands there. She won't move. She won't do anything unless you take her hand and actually take her somewhere. ${ }^{77}$

One teacher in the community discussed the idea that poverty itself is a disability.

That's a big thing to say: that poverty is linked to a disability ... but that's where all these guys are coming from ... They wake up, they don't have breakfast. They have to do what they have to do. They can't have a shower in the morning. If you're putting up with that every day, then you're trying come to school and learn ... I think if there [are] things on the whole that consistently prevent someone from learning then they're being disabled to achieve their best. ${ }^{78}$

Socioeconomic inequalities are not generally within the purview of discrimination law. However, where poverty or social disadvantage leads to the same behaviours that might arise from a disability, creating institutions that are experienced in accommodating challenging behaviours will benefit participants other than those who would meet the definition of disability. If the focus is on how students are 'disabled' by institutions rather than whether they have a 'disability', other vulnerable children will benefit.

\section{Should We Take the 'Disability' Out of Disability DisCRIMINATION LAWs?}

Given the problems with discrimination law dealing effectively with challenging behaviour - the emphasis on diagnosis when there may be none; the multiple and intersecting definitions of disability; a lack of understanding of behaviour as a disability and the contextual nature of it, along with the distinction between accommodating challenging behaviour that arises from disability and behaviour that arises from disadvantage or trauma - is there a better way to approach challenging behaviour? Can disability be thought of differently in discrimination, for the better protection of people with challenging behaviour? It might be preferable to remove the definition of disability from discrimination law altogether.

$77 \quad$ Interview with an educator (2014).

78 Interview with an educator (2014). 
What would happen if we removed the definitional hurdle, and did not require individual evidence of disability? This would not make disability irrelevant in implementing discrimination laws, since, as pointed out above, the 'reasonableness' requirement in indirect discrimination and making adjustments would still include consideration of the nature of an individual's needs and abilities. However, it would skip the first hurdle in proving a disability discrimination case: the complainant would not have to prove that he or she had a disability in order to access legal protection. Instead, by moving straight to the question of whether discrimination occurred, the first and most crucial emphasis is on the institution. Did the school create a situation in which a child was unable to learn? In employment, did the employer create an environment in which a person was unable to perform their work? This could be done by defining the respondent as 'disabling' rather than the individual complainant as 'disabled'. ${ }^{79}$ While the 'reasonableness' requirement in making adjustments and indirect discrimination would still mean that the individual attributes of the complainant would be relevant in determining whether an institution or individual was reasonably or unreasonably 'disabling', this would be considered in the context of institutional factors. There would not be a focus on the individual attributes of the complainant outside of the context in which the alleged discrimination occurs. This would create an important shift away from a stigmatising and, I argue, unnecessary, focus on the individual's impairment, which begins to set in place some of the negative consequences that can flow from the focus on the individual.

Each of the difficulties identified here for students with behavioural disabilities - the unnecessary requirement of medical diagnosis, the confusion of multiple competing definitions of disability, the lack of understanding of 'emerging' and invisible disabilities, the tendency to ignore contextual and environmental impacts on behaviour, and the fact that disadvantage other than impairment can also cause behavioural 'disabilities' - could all be mitigated by removing an individual definition of disability from discrimination law. It would mean, to return to some of the examples raised in this article, that a child whose IQ is a little too high to be diagnosed with an intellectual disability, or a child who is coming to school with behaviour issues arising from transitory conditions of stress or hunger, or a child whose behaviour is being managed outside

$79 \quad$ For example, the section of the Disability Discrimination Act 1992 (Cth) dealing with indirect discrimination (s 6(1)) could be amended to read: 'For the purposes of this Act, a person (the discriminator) discriminates against another person (the aggrieved person) if: (a) the discriminator requires, or proposes to require, the aggrieved person to comply with a requirement or condition; and (b) the aggrieved person is not able or would not be able to comply, with the requirement or condition; and (c) the requirement or condition has, or is likely to have, the effect of disabling that person.' Similarly, direct discrimination (s 5) could be directed at treatment that has, or is likely to have, the effect of disabling a person. 
of the medical system, could still be covered by disability discrimination laws if an institution is not reasonably accommodating their needs, or is subjecting them to requirements they cannot reasonably meet. While some of these may potentially have protection under the law, removing the definitional hurdle simplifies and clarifies this.

This article is a first step in thinking about whether removing the current definition of disability could strengthen discrimination law. If a nuanced social and human rights model is adopted, and disability, including behaviour, is genuinely accepted as a co-creation of individuals in a particular social and environmental context, a shift away from the largely negative focus on individual deficits is needed. Attention instead would rest on the 'disability' of the institution, and discrimination law would no longer reinforce stigma by insisting upon a declaration of individual impairment. Currently, disability discrimination law requires that an individual take on an identity attribute in order to access the protection of law, but it is a stigmatised identity that comes with its own disadvantages. Instead of having an individual argue that they are disabled, locating the disability in a 'disabling' institution is a way of acknowledging that disability, as well as behaviour, is a social responsibility rather than an individual attribute.

\section{CONCLUSION}

Despite its broad definition of disability, the explicit inclusion of behaviour, and its anchoring in the social model of disability, the Disability Discrimination Act has not offered sufficient protection to people with challenging behaviour seeking inclusion in public life. The definition in the CRPD offers a means of disrupting the way we currently deal with disability in law. Disability, coupled with an emphasis on diagnosis, has been read narrowly when it comes to behaviour in the case law. The contextual, constructed quality of behaviour is overlooked in favour of the individual and medical aspects of impairment. Along with this is a lack of understanding of how to address the more complex project of including people with difficult behaviours in public institutions of school and work. Despite this, the case of challenging behaviour offers a way of thinking about discrimination law in new and creative ways. In particular, since behaviour, like disability, takes its meaning from the social attitudes of a specific time and place, it invites us to look beyond the categories and definitions that structure discrimination law to see who, in its current manifestation, is still excluded from public life. 